\title{
Article
}

\section{The FVF framework and target prevalence effects}

Menneer, Tamaryn, Godwin, Hayward, Liversedge, Simon Paul, Hillstrom, Anne P., Benson, Valerie, Reichle, Erik and Donnelly, Nicholas

Available at http://clok.uclan.ac.uk/22330/

Menneer, Tamaryn, Godwin, Hayward, Liversedge, Simon Paul ORCID: 00000002-8579-8546, Hillstrom, Anne P., Benson, Valerie ORCID: 0000-0002-03514563, Reichle, Erik and Donnelly, Nicholas (2017) The FVF framework and target prevalence effects. Behavioral and Brain Sciences, 40 . e147. ISSN $0140-525 X$

It is advisable to refer to the publisher's version if you intend to cite from the work. http://dx.doi.org/10.1017/S0140525X16000170

For more information about UCLan's research in this area go to http://www.uclan.ac.uk/researchgroups/ and search for <name of research Group>.

For information about Research generally at UCLan please go to http://www.uclan.ac.uk/research/

All outputs in CLoK are protected by Intellectual Property Rights law, including Copyright law. Copyright, IPR and Moral Rights for the works on this site are retained by the individual authors and/or other copyright owners. Terms and conditions for use of this material are defined in the policies page.

\section{CLoK}

Central Lancashire online Knowledge www.clok.uclan.ac.uk

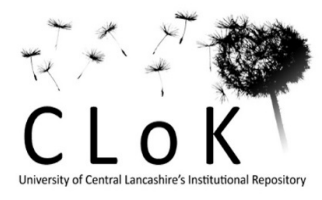


Commentary on Hulleman and Olivers

Evaluating the FVF framework and applying it to target prevalence effects

Tamaryn Menneer, Hayward J. Godwin, Simon P. Liversedge, Anne P.

Hillstrom, Valerie Benson, Erik D. Reichle, and Nick Donnelly.

University of Southampton

Short title: The FVF framework and target prevalence effects

This version accepted for publication in Behavioral and Brain Sciences on 19 February 2016. 


\begin{abstract}
The Functional Visual Field (FVF) offers explanatory power. To us, it relates to existing literature on the flexibility of attentional focus in visual search and reading (Eriksen \& St. James, 1986; McConkie \& Rayner, 1975). The target article promotes reflection on existing findings. Here we consider the FVF as a mechanism in the Prevalence Effect in visual search (PE).
\end{abstract}




\section{Commentary}

The focus on simulating the way in which slope gradients are influenced by the difficulty of search provides a backdrop to the thoughtful discussion. However there is a risk in simulating only these data, that the usefulness of the FVF framework may be seen as limited. To help overcome this limitation we have reanalysed some existing data from an experiment on the Prevalence Effect (PE; Wolfe, Horowitz, \& Kenner, 2005) to explore if this can provide some support for the FVF framework, and the usefulness of the FVF framework in furthering our understanding of attentional effects in visual search.

The PE refers to the influence that target probability has on both target selection and verification (e.g., Godwin, Menneer, Riggs, Cave \& Donnelly, 2015b; Hout, Walenchok, Goldinger, \& Wolfe, 2015). Frequently occurring targets tend to be found and verified quickly. In contrast, their absence is reported slowly. Infrequent targets have their presence reported slowly and their absence reported quickly.

In the target article, the modulating effect that target discriminability has on search reaction times is accounted for solely by changes in size of the FVF. As such, reaction times in search are solely a function of the size of FVF. Might differences in reaction times in the PE be contributed to by differences in the size of the FVF? Specifically, high target prevalence might lead to participants initially adopting a broader FVF than when target prevalence is low. A relatively broad FVF would allow the presence of targets to be detected quickly whereas a 
relatively narrow FVF would lead to slowed target detection. In deriving these hypotheses, we have made two assumptions. First, and to account for slow target-absent responses when target prevalence is high, we assume that failure to find evidence of target presence when the FVF is broad leads to a dynamic resizing of the FVF to allow, at the limit, item-by-item analysis (note that a global-to-local fixation pattern is consistent with recent consideration of search, Godwin, Reichle, \& Menneer, 2014; Over, Hooge, Vlaskamp, \& Erkelens, 2007). Second, that the fixation point of a broadened FVF is more likely to be centrally than peripherally positioned. For a broad FVF, a central fixation will encompass more items than a non-central fixation will. These reduce to a hypothesis that, early in search, fixations are more centrally biased in high-prevalence than lowprevalence search.

To test this hypothesis, we reanalysed data on target-present trials from Godwin, Menneer, Cave, Thaibsyah, and Donnelly (2015a). Space restrictions prohibit a full account of these data and analyses. Briefly, to assess the patterns quantitatively, the distribution of fixation locations across displays were normalised within high- and low-prevalence conditions and split into fixations made early and late in search (as defined by median split). $z$-scores for the differences, between high- and low-prevalence conditions were calculated for these normalised data. The striking finding is that increasing prevalence is associated with more fixations to the centre of search displays early in search. While a centre bias (Tseng, Carmi, Cameron, Munoz, \& Itti, 2009) was present early in low-prevalence search, the bias is significantly stronger under high prevalence. 
These data are, then, consistent with the FVF framework. However, our objective is not to claim that our reanalysis of how prevalence affects eye movements made during search provides unequivocal support. Rather, that the framework's articulation has provided a useful stimulus to reconsidering data in a way that provides an additional account of how search patterns might change with target prevalence.

The current utility of the FVF is tempered, in our view, by two limitations. First, the current focus on numbers of fixations precludes the influence of fixation duration. Increasing cognitive demands affects both the number and duration of fixations (Liversedge \& Findlay, 2000). Consequently, any comprehensive framework of search behaviour must explain both fixation number and duration. In fact, recent evidence suggests that fixation durations during visual search are controlled on the basis of a trade-off between making rapid fixations while also allowing time to examine objects in the display (Godwin, Reichle, \& Menneer, in press). As a consequence, there have been calls for a greater understanding of fixation duration variability during visual search tasks (Reingold \& Glaholt, 2014).

Second, the authors rightly wish to extend consideration to searching in scenes. As the search environment becomes richer in contextual information, equation of selection time, processing time, and dwell time to fixation time (pp. 52-53) becomes more challenging. In reading, "spill-over effects" are frequently observed (whereby a linguistic influence of one word is seen to affect fixations 
on it and later words in the sentence; Rayner \& Duffy, 1986). By extension, visual search in scenes may also be subject to partial dissociation between fixation location and the set of locations from which information is currently being processed. To this extent, evaluation of effects across temporally contiguous fixations as well as spatially contiguous fixations is a critical issue for theoretical development.

In sum, we consider the FVF framework as a useful stimulus to rethink visual search. Here we have provided some provisional data that might support the FVF. In addition, two areas of concern to be addressed in future developments have been noted.

\section{References}

Eriksen, C. W., \& St. James, J. D. (1986) Visual attention within and around the field of focal attention: A zoom lens model. Perception and Psychophysics, 40, $225-240$.

Godwin, H.J., Menneer, T., Cave, K.R., Thaibsyah, M., \& Donnelly, N. (2015). The effects of increasing target prevalence on information-processing during visual search. Psychonomic Bulletin \& Review, 22(2), 469-475.

Godwin, H.J., Reichle, E.D., \& Menneer, T. (2014). Coarse-to-fine eye movement behavior during visual search. Psychonomic Bulletin \& Review, 21, 1244-1249. 
Godwin, H.J., Reichle, E.D., \& Menneer, T. (In press). Modeling lag-2 revisits to understand trade-offs in mixed control of fixation termination during visual search. Cognitive Science.

Godwin, H.J., Menneer, T., Riggs, C.A., Cave, K.R., \& Donnelly, N. (2015). Perceptual failures in the selection and identification of low-prevalence targets in relative prevalence visual search. Attention, Perception \& Psychophysics 77, 150-159.

Hout, M. C., Walenchok, S. C., Goldinger, S. D., \& Wolfe, J. M. (2015). Failures of perception in the low-prevalence effect: Evidence from active and passive visual search. Journal of Experimental Psychology: Human Perception and Performance.

Liversedge, S.P., \& Findlay, J.M. (2000). Eye movements reflect cognitive processes. Trends in Cognitive Sciences, 4, 6-14.

McConkie G.W., \& Rayner K. (1975). The span of the effective stimulus during a fixation in reading. Perception \& Psychophysics, 17, 578-586.

Over, E. A. B., Hooge, I. T. C., Vlaskamp, B. N. S., \& Erkelens, C. J. (2007). Coarse-to-fine eye movement strategy in visual search. Vision Research, 47, 2272-80. doi:10.1016/j. visres.2007.05.002

Pollatsek A., Bolozky S., Well A.D., \& Rayner K. (1981). Asymmetries in the perceptual span for Israeli readers. Brain and Language, 14, 174-180.

Pollatsek, A., Raney, G.E., Lagasse, L. \& Rayner, K., (1993). The use of information below fixation in reading and in visual search. Canadian Journal of Experimental Psychology, 47,179-200. 
Rayner, K., \& Duffy, S. A. (1986). Lexical complexity and fixation times in reading: Effects of word frequency, verb complexity, and lexical ambiguity. Memory \& Cognition, 14, 191-201.

Reingold, E. M., \& Glaholt, M. G. (2014). Cognitive control of fixation duration in visual search: The role of extrafoveal processing. Visual Cognition, 22(3), $1-25$.

Stoffer, T. H. (1993). The time course of attentional zooming: A comparison of voluntary and involuntary allocation of attention to the levels of compound stimuli. Psychological Research, 56, 14-25.

Tseng, P., Carmi, R., Cameron, I. G. M., Munoz, D. P., \& Itti, L. (2009). Quantfying center bias of observers in freee viewing of dynamic natural scenes. Journal of Vision, 9(7), 1-16.

Wolfe, J. M., Horowitz, T. S., \& Kenner, N. M. (2005). Rare items often missed in visual searches. Nature, 435, 439.

Yantis, S., \& Jonides, J. (1990). Abrupt visual onsets and selective attention: voluntary versus automatic allocation. Journal of Experimental Psychology: Human Perception and Performance, 16(1), 121. 